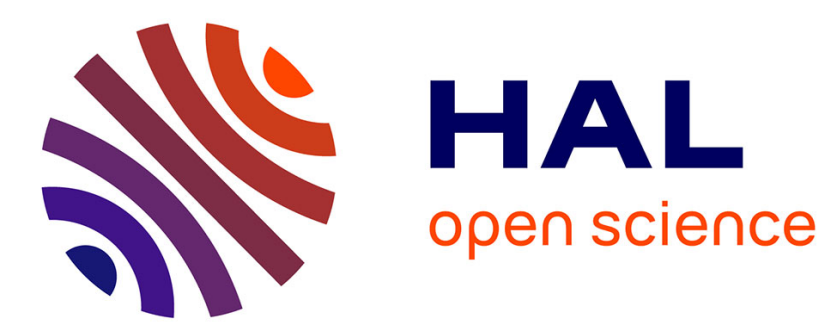

\title{
A Framework for Analyzing Business/Information System Alignment Requirements.
}

Islem Gmati, Selmin Nurcan

\section{To cite this version:}

Islem Gmati, Selmin Nurcan. A Framework for Analyzing Business/Information System Alignment Requirements.. International Conference on Enterprise Information Systems, 2007, Portugal. pp.1. hal-00706193

\section{HAL Id: hal-00706193 \\ https://hal.science/hal-00706193}

Submitted on 15 Jun 2012

HAL is a multi-disciplinary open access archive for the deposit and dissemination of scientific research documents, whether they are published or not. The documents may come from teaching and research institutions in France or abroad, or from public or private research centers.
L'archive ouverte pluridisciplinaire HAL, est destinée au dépôt et à la diffusion de documents scientifiques de niveau recherche, publiés ou non, émanant des établissements d'enseignement et de recherche français ou étrangers, des laboratoires publics ou privés. 


\title{
A FRAMEWORK FOR ANALYZING BUSINESS/INFORMATION SYSTEM ALIGNMENT REQUIREMENTS
}

\author{
Islem Gmati ${ }^{1}$, Selmin Nurcan ${ }^{1,2}$ \\ ${ }^{1}$ Université Paris 1- Panthéon Sorbonne \\ Centre de Recherche en Informatique, \\ 90, rue de Tolbiac 75634 Paris cedex 13, France \\ ${ }^{2}$ IAE de Paris (Sorbonne Business School) - Université Paris 1 - Panthéon Sorbonne \\ 21, rue Broca 75005 Paris France \\ Islem.Gmati@malix.univ-paris1.fr , Selmin.Nurcan@univ-paris1.fr
}

Keywords: strategic alignment, evolving environment, information system flexibility and evolution capacities.

\begin{abstract}
In order to provide a competitive advantage to the enterprise, the business strategy and processes and its information system (IS) need to be aligned. Achieving strategic alignment continues to be a major concern for business executives and becomes more difficult to handle in an evolving environment. The literature provides conceptual frameworks dividing a company representation in independent and exchanging layers and aiming at the strategic alignment. In this paper, we describe eight among these works. Aiming a better understanding of the Business/IS alignment requirements, we propose an analysis framework, in which we position the studied approaches, and we bring out the most important results related to the forces and weaknesses of these approaches.
\end{abstract}

\section{INTRODUCTION}

Today, organizations evolve in a competitive and changing environment that can be at the origin of factors or forces, which oblige them to change. Thus, to survive and to remain competitive, a company has to evolve in adequacy with its environment.

In the course of time, we noted that organizations change their processes and their strategy to respond to constraints of the environment, but their information systems remain often unchanged. However, an organization cannot work efficiently if it does not have a coherent information system (IS). Thus the problem of the strategic alignment arose often when the need to make "move" the IS in phase with the strategy of the company is identified. Indeed, in a quickly evolving environment, companies have to adapt constantly their IS in order to comply more effectively with the constraints of new technologies, new needs and/or new rules. Moreover, it is not possible to stop the IS to build another one, it should rather evolve in a continuous way in order to remain in correspondence with the organization strategy. We can talk about the flexibility and the evolution capacities of the IS.

Furthermore, change often influences the organization as a whole, from company strategy to the business processes and the IS. To remain competitive in changing environments, it is very important that companies align their IS on their organizational processes, their goals and their strategies (Campbell et al. 2004). Even if the interest of the alignment is widely recognized, its realization remains too often limited. Few leaders consider that the IS and the processes of their organization are aligned (Adams et al. 2003). Luftman and Maclean (2004) identifies two main causes: (i) the actors of the organization do not know what the alignment is and (ii) there is an 
absence of communication and understanding between the world of the business and that of information technologies (IT).

For a comprehensive study of the alignment requirements, we developed a framework based on four perspectives called also worlds (Jarke et al., 1990). Each world is characterized using facets, which are composed of attributes. Nevertheless, we point out that only the perspectives and the structure of the framework are generic. Facets and attributes were defined for the purpose of this study. They characterize the requirements that we identified as essential for analyzing and comparing the Business/IS alignment methods, approaches or frameworks. Our long-term research objective is to enhance the IS engineering approaches and practices with those requirements in their early phases. Section 2 presents eight approaches on Business/IS and Business/ Strategy alignments. Section 3 presents the developed framework and Section 4 analyzes the presented approaches with respect to the proposed framework.

\section{STATE OF THE ART}

The strategy and the objectives of any enterprise are achieved by implementing business processes (BPs) which are supported/facilitated by the enterprise IS. It seems not realistic to consider an organizational change without any impact on the IS or an evolution of the IS which does not call any change on BPs or objectives of the enterprise (Nurcan \& Edme, 2005). Section 2.1 presents approaches from the literature which purposes are to align the IS on the business (more especially to its way-of functioning). These approaches help to understand and to exploit the relationships between the BPs and the systems that are supposed to support and to guide their execution. Section 2.2 presents approaches that aim to specify the links between the strategy of a company and the implemented BPs. Finally, section 2.3 recalls the work of Kaplan and Norton (1996) that offers a completely different glance on various perspectives of a company and the relationships between them. We tried to highlight the strengths of those approaches in order to define the facets of our analyzis framework.

\subsection{Business/IS aligment}

\subsubsection{ARIS framework ${ }^{(1)}$}

Scheer and Nuttgens (2000) present the Architecture of Integrated Information System (ARIS) that is composed of four interdependently connected layers: process engineering, process planning and control, workflow control and application systems. The process engineering layer provides techniques for optimizing, evaluating and ensuring the quality of processes. Reference models provide an initial process engineering solution and document process know-how that can be reutilized for further modeling. The process planning and control layer describes current BPs based principally on the cost analysis. The first two layers concern business managers. The workflow control layer converts BPs into IT support and is responsible for the execution of BPs. In the application systems layer, information and documents delivered to the workplaces are specifically processed.

\subsubsection{The Integrated Enterprise Framework ${ }^{(2)}$}

To remain competitive, organizations must be able to adapt quickly their way of providing services and products when change occurs. Papazoglou and Van den Heuvel (2000) provide a methodology which purpose is to link enterprise models to wrapped legacy system modules, namely BALES (binding Business-Applications to Legacy systems) methodology. This methodology reveals also how such mappings can address business change requirements. This framework contains five layers. The business objects layer plays a central role in capturing the semantics of business entities and processes. The BPs layer aims to provide generic BPS and a set of basic building blocks. The workflow layer assigns BPs to actors, and moves the work forward from one actor to the next. Workflow activities may invoke components from existing applications, for instance legacy objects, and combine them with newly developed applications. Business objects and BPs are oriented towards the fulfillment of business goals. BALES prescribes a two-step approach to incorporate business change: (i) To adapt existing enterprise model to reflect the new business reality; (ii) To determine a new mapping between enterprise models and legacy systems.

\subsubsection{The approach of Longepe ${ }^{(3)}$}

Longepe (2004) distinguishes four layers of enterprise and IS architecture: business, functional, applicative and technical. The business architecture describes the organization structure with regard to its business activities. An activity constitutes a stage of a business process and specifies the achievement of a business goal. Functions are derived starting from the activities and going from macro functions to elementary ones. The latter are defined in one-to-one correspondence with the services supported by IS. The elementary functions are organized in the functional architecture. Two approaches allow mapping business and functional layers. The top down approach (i) starts from the strategy of the company, (ii) deduces for 
each business objective the BPs allowing to achieve it and for each business activity the IS functionalities supporting it, and (iii) defines finally the support system. The bottom up approach starts from the operations performed by actors and elicits the business organization and objectives requiring those operations. The applicative architecture allows structuring the support system in communicating software components. In the technical architecture, the technical components as well as the information (source, model, documentation,...) related to the life cycle of the system are defined.

\subsubsection{The approach of Wieringa ${ }^{(4)}$}

Wieringa et al. (2003) proposes an integrated framework for the co-design of the BPs and the IS architecture, in which the business and the supporting applications form a reactive system. This work provides a classification of system properties and highlights the classical distinction between process and product. The product may be an IS or an enterprise architecture and has functional and quality properties. The former are services offered to the environment, and the latter characterize the value that the system provides for its stakeholders. Three functional properties characterize system services: (i) the behavior aspect consists of the ordering of services over time, (ii) the communication aspect consists of the interactions with other entities (people, devices, businesses, and software) during the delivery of the service, and (iii) the semantic aspect consists of the meaning of the symbols exchanged during the service. In general, entities at one layer use services of entities at lower layers and provide services to entities at higher layers. Finally, the refinement dimension allows describing entities belonging to a service level at a higher level of abstraction (fewer details) or at a higher level of refinement (more details).

\subsubsection{SEAM methodology ${ }^{(5)}$}

Wegman (2003) considers the enterprise as a complex system which key characteristics is its continuous evolution. A SEAM (Systemic Enterprise Architecture Methodology) project is iterative because its environment continuously evolves. Thus the enterprise architecture model can be adapted to represent the changes which occur (on the business level or the IS level). SEAM provides three kinds of development activities. (i) The goal of the multi-level modeling is to produce a new model, or to modify an existing model of the enterprise. (ii) The goal of the multi-level design is to identify gaps between As-Is and To-Be representations and to reduce them. (iii) The goal of the multi-level deployment is to transform what is described in the organizational levels for the To-Be state in artifacts that can be executed by people or software systems.

\subsubsection{Synthesis}

The main objective of the studied approaches is to specify and to control organization in a flexible way in order to gain the ability to adapt it to the market conditions. All of them try to reconfigure BPs to satisfy the environment changing requirements. To this end, they allow to:

- specify the enterprise architecture using several layers of representation, considering that each layer adds a new perspective (from models on objectives and processes to executable software components) to the higher layer but do not specify how to map those layers,

- simulate and evaluate BPs in order to improve their efficiency,

- develop links between the reconfigured processes and the new applications built on the legacy ones by adding new functionalities, and

- suggest to decompose the support system into loosely coupled small modules (interoperability requirement).

\subsection{Business/Strategy alignment}

\subsubsection{Strategic Alignment Model (SAM) ${ }^{(6)}$}

Henderson and Venkatraman (1989) developed a model for conceptualizing the strategic management of information technology (IT). The Strategic Alignment Model (SAM) makes a distinction between the external perspective of IT (IT strategy) and the internal focus of IT (IT infrastructure and processes). The same distinction is done for the business domain. This implies two types of integration: (i) strategic integration between IT (strategy) and business (strategy) which establishes the capability of IT at a strategic level, and (ii) operational integration between IT infrastructure and processes and organizational internal infrastructure and BPs. SAM proposes four domains of strategic choice: business strategy, IT strategy, organization infrastructure and processes, and IT infrastructure and processes. The change cannot occur in a field without influencing the others. The model provides also two types of alignment: strategic fit (between external and internal domains) and functional integration (between business and technology domains). Authors argue that neither strategic nor functional integration alone is sufficient to perform Business/Strategy alignment.

\subsubsection{EKD-CMM approach $^{(7)}$}

EKD-CMM (Enterprise Knowledge Development - 
Change Management Method) (Barrios \& Nurcan, 2004) is a method to documenting an enterprise, its objectives, BPs and support systems, helping enterprises to consciously develop schemes for implementing changes. The inter-connected set of EKD-CMM models describing an enterprise is structured in three layers: Enterprise Goal Model, Enterprise Process Model and Enterprise IS Model. The first two layers focus on intentional and organizational aspects of the enterprise. The third layer allows defining the requirements for an information system. EKD-CMM satisfies two needs: assisting enterprise knowledge modeling and guiding the enterprise modeling and the organizational transformation processes.

\subsubsection{The Bleistein's approach ${ }^{(8)}$}

Bleistein et al. (2005) proposes an unified model to enable validation of system requirements with regard to the business strategy. The aim is to incorporate an explicit understanding of business strategy within requirements engineering activities as a means of ensuring alignment between requirements for a system and the business strategy it is intended to support. This is based on a framework, called the Motivation Model (proposed by the Business Rules Group), which describes the semantics of a business strategy and its alignment with technology without proposing any specific means of representation. Considering similarities between BRG-Model and I*, Bleistein et al. applied I* to BRG-Model with the aim of unifying the business strategy model with the system requirements model. The approach proposes to use a technique to analyze the business strategy (VMOST) and to model it using a goal-oriented notation. It also suggests using context diagrams resulting from Jackson's problem diagrams. The goal model helps to ensure that requirements, at lowest levels, are in harmony with and provide support for objectives of the business strategy at higher levels. Problem diagrams help to situate requirements explicitly in the context to which they refer.

\subsection{Another vision of the organization}

The Balanced Scorecard (BSC) approach was developed for the strategic management at the beginning of the 90's in order to provide a clear prescription of the performance measurement. The BSC allows analyzing the organization according to four perspectives, or axis, interconnected by "causeeffect" relations that draw the strategy of the organization:
- The financial axis includes the long-term objectives of the company.

- The customer axis identifies the market segments on which the company wishes to be competitive.

- The internal processes axis includes the essential BPs to implement in order to achieve objectives of customers and shareholders.

- The organizational learning axis develops internal objectives and organizational means to improve the satisfaction of stakeholders and to facilitate thus facilitate the achievement of the objectives of the three other axes.

The BSC is a frame, which allows to integrate strategic indicators and to propose performance determiners relative to these four axes. These determiners lean on a translation of the organization strategy in objectives and concrete indicators.

\section{ANALYSIS FRAME}

To build our analysis frame, we were inspired of the work presented in (Jarke et al., 1990), (Rolland, 1998) the "four worlds" framework. The subject world contains the knowledge of the domain about which the system world has to supply information. In our case, the subject is the strategic alignment. The system world contains the models to represent the subject world. The usage world describes the organizational environment of the system, i.e. the goals of the actors and the way they use the system to carry out their work; this world allows also analyzing the objectives of the strategic alignment. The development world concerns the engineering process that allows us to build the various models of the system world. To study and to compare the various aspects of the studied approaches, facets characterize each world. A facet defines a particular aspect of an approach. It is composed of a set of attributes that allow us to clarify, through the possible values, the position of an approach with regard to the others. The values of attributes can be of a predefined type (integer, boolean ...) or an enumerated type (Enum $\{x, y\}$ ).

\subsection{The Subject World}

Our universe of discourse concerns the strategic alignment. Two facets characterize it:

A. Nature of the alignment: it is defined by a unique attribute Nature. In the literature, we distinguished four types of alignment. The business/IS alignment consists in understanding and exploiting the relations between the business processes and the system to be built. The strategy/business alignment consists in specifying 
the links between the objectives of the company and the implemented business processes. The business strategy/IT strategy alignment represents the link between the business and the IT strategies. More specifically, the latter takes in charge the capacity of the technology to determine and to support the business strategy. The IT strategy/IS alignment explains how the strategic use of IT can serve the agility of the IS. This presents an innovative character that limits its taking of consideration in the planning initiatives.

B. Nature of the change: this facet is characterized using two attributes:

a. Nature: the literature provides various types of change for BPs:

- Ad hoc: the change is made in a dynamic way during the process performance.

- Evolutionary: it is often the result of an effort of reorganization aiming processes reengineering by improving their behavior.

- Corrective: occurs when an error is perceived during the realization of the process.

b. Origin: according to (Barrios, 2001), two types of contextual forces can cause the change in the organization: internal and external. Internal forces issues from the organization need and/or wish to grow or to evolve. External forces are constraints imposed by the external environment of the organization.

Nature of the alignment:

Nature: Enum $\{$ business/IS alignment, strategy/business alignment, business strategy/IT strategy alignment, IT strategy/SI alignment $\}$

Nature of the change:

Nature: Enum \{ad hoc, evolutionary, corrective\} Origin: Enum \{internal, external\}

\subsection{The Usage World}

The objectives assigned to the alignment between the various organization representation layers and the intentions of the individuals, which manage this alignment, are the purpose of this world. Four facets allow defining them:

A. Purpose of the alignment: this facet is characterized by one attribute Purpose. To align the enterprise global model elements, the company tries to adapt its BPs to the changes, to improve them in order to better achieve its goals and to build new BPs in order to integrate new functionalities. If the alignment already exists between these elements, the company tries to maintain it.

B. Strategic alignment. this facet characterized by the attribute Alignment perspectives can take four values corresponding to the four perspectives cited in the SAM
(Henderson \& Venkatraman, 1999) according to the business strategy or the IT strategy is the driving force.

- Strategy execution: this perspective views the business strategy as the driver of both organizational design choices and the design of IS infrastructure. IT management only implements the strategy formulated by the top management.

- Technology transformation: this perspective views also the business strategy as the driver but is not constrained by the organization design. However, it involves the formulation of an IT strategy that support the chosen business strategy and the articulation of the required IS infrastructure and processes.

- Competitive potential: unlike the two previous perspectives that considered business strategy as given, this perspective allows the modification of business strategy (and the organizational infrastructure and BPs) via emerging IT capabilities.

- Service level: this perspective focuses on how to build a world-class IS service organization. In this perspective, the role of business strategy is indirect. This perspective is often viewed as necessary (but not sufficient) to ensure the effective use of IT and to be responsive to the growing and fast-changing demands of the end-users.

C. The communication constitutes an essential mean to support the strategic orientation of the organization. Indeed, experts from various departments have to communicate in order to share information and ensure awareness of the smallest problem.

D. The comprehension of the user represents the facility of comprehension of requirements related to the alignment by the involved actors.

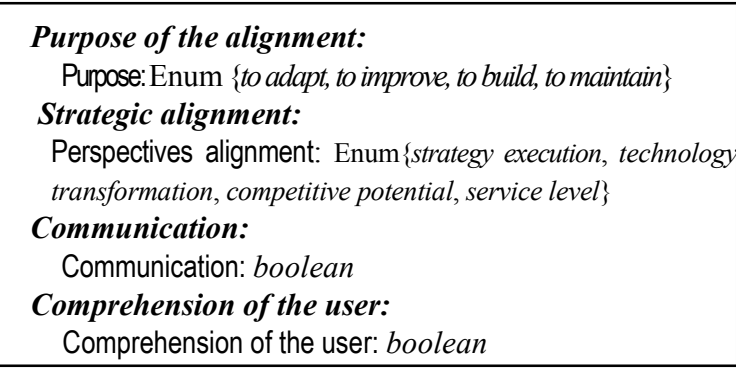

\subsection{The System World}

The system world is related to the representation of the IS supporting the BPs and the organization strategy as well as the representation of the alignment between them. We define six facets. Five of them, cover, refinement, traceability, modularization and capture of the change are characterized by an attribute of the same name: 
A. The cover allows capturing the capacity of the models to represent the knowledge relative to the strategic alignment. We distinguish activity, product, context, decision and intention oriented models.

B. The refinement specifies the model contents. Models can include knowledge related to various layers of interest namely: intentional, organizational, IS and technological layers.

C. The traceability is the capacity to draw explicit relationships between the elements of the connected models (Wegman, 2003).

D. The flexibility: a flexible IS has the ability to be adapted to the BPs changes. This facet is measured by four attributes:

a. The modularization allows decomposing enterprise models into significant chunks. It facilitates the comprehension of the user and the reuse of the chunks.

b. The capability to re-use existing components is an essential requirement in order to build a flexible IS. Indeed, if a change occurs, the system has to evolve in accordance with the new reality where legacy systems often remain. So, those legacy components have to be re-used, instead of completely re-design the whole system.

c. In order to be flexible, the system has to be able to capture the change. Indeed, a system cannot adapt itself to its environment if it is not able to detect the changes which occur (Sadiq \& Orlowska, 1998). This attribute can take three values: no if the way of capturing the change is not defined, trigger if such a concept allows activating the modifications and other if another method is used.

Cover:

Cover: Enum \{activity, product, context, decision, intention\}

Refinement:

Refinement: Enum \{intentional, organizational, SI, technological\}

Traceability:

Traceability: boolean

Flexibility:

Modularization: boolean

Re-use of the existing components: boolean

Capture of the change: Enum \{no, trigger, other\}

\subsection{The Development World}

The development world handles the engineering process of the IS which representations are stored in the system world. In our case, the development world concerns the IS engineering process models and integrates the requirements of the strategic alignment for creating as as well as for maintaining the fit between business (strategy and processes) and IS. We are particularly interested in the aspects of IS engineering, defined in three facets:
A. Development approach characterized by three attributes:

a. The nature of the development process, it can be $a d$

hoc or systematic.

b. The paradigm of modeling: the values of the attribute "Cover" (system world) for business process to be modeled, remain valid for the IS engineering processes.

c. The capitalization of knowledge aims to promote the use of the established enterprise knowledge that proved its effectiveness. It is a boolean.

$B$. The support provided for the IS engineering process is defined using two attributes:

a. The software support; it can be automatic, manual or mixed.

b. The infrastructure of execution: it has to be generic and/or interoperable in order to facilitate the integration of the existing objects into new applications.

C. The guidance: it provides a range of possibilities of actions by taking into account the level of organizational maturity, the delay obtained to master the change, etc... Several attributes can characterize the guidance, but we are interested in our analysis to the following ones:

a. Existence; it specifies if the development process is guided or not.

b. Granularity of the guidelines provided to guide IS engineers. Guidelines can be specified in a very general way, for instance, the definition of the major stages of the development process; or provide the details of all development activities, the handled resources and the situations in which these activities can be performed.

Development approach:
Nature of the devt process: Enum $\{$ ad hoc, systematic\}
Modeling paradigm: Enum \{context, decision,
intention, activity, product\}
Knowledge capitalization: boolean
Execution support:
Software support: Enum \{automatic, mixed, manual\}
Infrastructure of execution: Enum \{generic, inter operable\}
Guidance:
Existence: boolean
Granularity: Enum \{micro, macro\}

\section{Discussion}

The analysis framework developed above allowed us to identify the various aspects of the alignment approaches and to classify them. Based on this classification, it was possible to highlight the main characteristics of these approaches. The classification facilitates also to understand the needs of the IS in terms of adaptability and flexibility as well as the stakeholders requirements concerning the strategic 
alignment in terms of comprehension and communication between Business and the IT teams.

\begin{tabular}{|c|c|c|c|}
\hline World & Facets & Attributs & Approaches \\
\hline \multirow{3}{*}{ 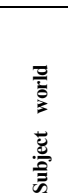 } & Alignment nature & nature & $\begin{array}{l}\text { Business/SI: 1, 2, 3, 4, 5, 6, 7; } \\
\text { Strategy/business: 6, 7, 8; Business } \\
\text { strategy/IT strategy: } 6 \text {; IT strategy/SI: } \\
\text { none }\end{array}$ \\
\hline & \multirow[t]{2}{*}{ Change } & Nature & $\begin{array}{l}\text { Ad hoc: } 1,4,7,8 \text {; Evolutionary: all; } \\
\text { Corrective: } 1,5\end{array}$ \\
\hline & & Origin & Interne, extern: $1,2,3,4,5,6,7,8$ \\
\hline \multirow{4}{*}{ 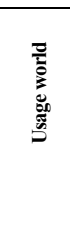 } & $\begin{array}{l}\text { Alignment } \\
\text { purpose }\end{array}$ & Purpose & $\begin{array}{l}\text { To adapt: all; to built: } 2,3,6 \text {; to improve: } \\
1,3,5,6,7 \text {; to maintain: } 4,5,7\end{array}$ \\
\hline & \begin{tabular}{|l|} 
Strategic \\
alignment
\end{tabular} & $\begin{array}{l}\text { Alignment } \\
\text { perspectives }\end{array}$ & $\begin{array}{l}\text { Strategy implementation: all, } \\
\text { Technology potential: 6; Competitive } \\
\text { potential: 6; Service level: } 6\end{array}$ \\
\hline & \begin{tabular}{|l} 
Communication \\
\end{tabular} & \begin{tabular}{|l} 
communication \\
\end{tabular} & Yes: $3,5,7,8 ;$ No: 1,$2 ;$ NS: 4,6 \\
\hline & $\begin{array}{l}\text { User } \\
\text { comprehension }\end{array}$ & $\begin{array}{l}\text { User } \\
\text { comprehension }\end{array}$ & Yes: $1,5,7,8 ; \mathrm{NS}: 2,3,4,6$ \\
\hline \multirow{6}{*}{ 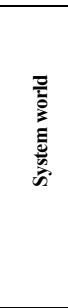 } & Cover & Cover & $\begin{array}{l}\text { Product Oriented: } 5 \text {; Activity Oriented: } \\
1,2,4,7 \text {; Context Oriented: none; } \\
\text { Decision Oriented: } 4,5,7 \text {; Intention } \\
\text { Oriented: } 7,8\end{array}$ \\
\hline & Refinement & Refinement & $\begin{array}{l}\text { Intentional: } 2,4,6,7,8 ; \text { Organizational: } \\
\text { all, SI: } 2,3,4,5,6,7 ; \text { Technologic: } 1,3 \text {, } \\
4,5,6\end{array}$ \\
\hline & \begin{tabular}{|l|} 
Traceability \\
\end{tabular} & \begin{tabular}{|l} 
Traceability \\
\end{tabular} & Yes: $2,3,5,7,8 ; \mathrm{NS}: 1,4,6$ \\
\hline & \multirow{3}{*}{ Flexibility } & Modularization & Yes: $1,2,3,4 ;$ No: $7 ;$ NS: $5,6,8$ \\
\hline & & $\begin{array}{l}\begin{array}{l}\text { Capture of the } \\
\text { change }\end{array} \\
\end{array}$ & Trigger: 2,$4 ; \mathrm{NS}: 1,3,5,6,7,8$ \\
\hline & & Re-use & Yes: $2,3,4 ;$ No: $7 ;$ NS: $1,5,6,8$ \\
\hline \multirow{7}{*}{ 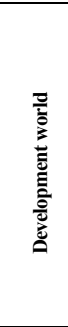 } & \multirow{3}{*}{$\begin{array}{l}\text { Development } \\
\text { approach }\end{array}$} & \begin{tabular}{|ll}
$\begin{array}{l}\text { Dev } \\
\text { nature }\end{array}$ & process \\
\end{tabular} & Ad hoc: $1,2,3,4,5,6,8 ;$ Systematic: 7 \\
\hline & & $\begin{array}{l}\text { Modeling } \\
\text { paradigm }\end{array}$ & $\begin{array}{l}\text { Contextual: 7; decisional: } 1,2,3,4,5 \text {; } \\
\text { Intentional: none; Product Oriented: } \\
\text { none, Activity Oriented: none; NS: } 6,8\end{array}$ \\
\hline & & \begin{tabular}{|l|} 
Knowledge \\
capitalization
\end{tabular} & Yes: 1,$7 ;$ No: $4,6,8 ; \mathrm{NS}: 2,3,5$ \\
\hline & \multirow[t]{2}{*}{ Execution support } & \begin{tabular}{|l} 
Software support \\
\end{tabular} & $\begin{array}{l}\text { Mixed: } 1,2,3,4,5 \text {; Automatic: } 7 \text {; } \\
\text { Manual: none; NS: } 6,8\end{array}$ \\
\hline & & $\begin{array}{l}\text { Execution } \\
\text { infrastructure }\end{array}$ & $\begin{array}{l}\text { Generic: } 1,2,3,4 \text {; Inter operable: } 2,3 \text {; } \\
\text { NS: } 5,6,7,8\end{array}$ \\
\hline & \multirow[t]{2}{*}{ Guidance } & Existence & Yes: 4,$7 ;$ No: $1,2,3,5,6,8$ \\
\hline & & \begin{tabular}{|l|} 
Granularity \\
\end{tabular} & Micro: 4; Macro: 7 \\
\hline
\end{tabular}

Concerning the characteristics of the IS engineering approaches to fulfill the alignment requirements, we retain as essential the traceability and the flexibility expressed by the re-use, the modularization and the capture of the change. The traceability is a relevant argument for the alignment between various organization representation layers (Longepe, 2004), (Wegman, 2003), (Bleistein et al., 2005).

The re-use is directly related to the change. According to the change requirements and to the situation in hand, the existing models are adapted to the new business reality or new applications are developed. Often, existing components (legacy systems) remain. Software components have to be modular and the most independent possible to be more easily re-used and adapted to the environment evolutions (Papazoglou \& Van den Heuvel, 2000), (Longepe, 2004).

We notice that the majority of the studied approaches use activity-oriented models to represent business processes (Scheer \& Nuttgens, 2000), (Longepe, 2004), (Papazoglou \& Van den Heuvel, 2000) and (Wegman, 2003). However, in a changing environment, the flexibility of the business process models is essential. Activity-oriented models offer a linear view, which is inadequate to represent flexible business processes. Few approaches offer decision-oriented or contextoriented models (Barrios \& Nurcan, 2004) which are more appropriate to represent business processes requiring flexibility.

Few of the presented approaches are able to capture changes (Scheer \& Nuttgens, 2000), (Wieringa et al., 2003) i.e. to define the way the various significant events occur. Some approaches use triggers (Scheer \& Nuttgens, 2000) and define exceptions that allow capturing changes. Nevertheless, the definition of exceptions supposes that changes should be foreseen. To summarize, we can affirm that the existing approaches are rather moderately adapted to the change handling.

With regard to the requirements of the alignment process, the communication between business and IT experts as well as their understanding of what is the alignment seem very important to us. The communication constitutes a good means to understand the change requirements and to propagate them on all units and levels of the company. Moreover, in order to maintain the alignment (when it exists), measures are useful to analyze the gaps between the current and the future situations. The strategy becomes really the affair of all if everybody understands it and is motivated to apply it (Kaplan \& Norton, 1996). The communication and the comprehension of the user are closely dependent concepts. Bleistein et al. (2005) indicate two success factors for defining the alignment between IS and business strategies : (i) the mutual comprehension of the business strategy between business and IS managers and (ii) the incorporation of this comprehension in the IS development.

An important aspect, which was neglected by the majority of the studied approaches and which constitutes a vital criterion for the companies, is the strategic links for the business as as well for the IT purposes. Indeed, to remain competitive and to ensure its adaptability, the company has to attach a great importance to its external environment and to integrate its requirements in its organizational and technological infrastructures (startegic fit). In spite of the importance of this aspect, we notice that it was approached only by (Henderson \& Venkatraman, 1989) which emphasizes also the importance of the IT strategy in the implementation of the business strategy (strategy integration). In the other approaches, even if the environment of the company and the strategic alignment were pointed in some of them (Wieringa et al., 2003), (Wegman, 2003), the importance of the IT domain was not explicitly specified. Other authors emphasize the role of information technologies. For instance, (Morton, 2001) makes several assumptions on this subject, among which: (i) IT allow a better efficiency on the 
value chain, (ii) IT allow an increase in the size, the complexity and the reactivity of the company while preserving its flexibility, (iii) IT raise the required level of competence but also the motivation of the staff. Indeed, these technologies changed radically our world, and a major importance is required in order to ensure effectively the strategy/business/IT alignment in the organizations.

\section{CONCLUSION}

In order to gain a comprehensive understanding of the alignment requirements, it seemed relevant to us to define an analysis framework. We built our framework on the "four worlds" (Jarke et al., 1990) which already proved efficiency in several disciplines like IS engineering or requirements engineering. Facets and attributes of each world were specifically developed for analyzing and comparing Business/IS alignment abilities of IS engineering methods and frameworks. Once the framework was established, we used it to analyze eight approaches aiming to the alignment between business (strategy and processes) and IT. The definition of this framework and the various analyses we performed highlighted three important concepts:

- The communication between the specialists of the company constitutes a good means to share knowledge and to better understand the organization strategy and consequently to facilitate its implementation.

- The flexibility of business and IS processes that constitutes an important characteristic in an evolutionary environment since it can allow the IS to serve the strategy of the company and to change in adequacy with it.

- The importance of the integration of IT capabilities in the business strategy. Indeed, considering the importance of the IT, decision makers have to acquire a sufficient comprehension of them, in the strategy of the company, in order to exploit them effectively.

The opportunities related to the potential of the IT, the motivation and the coordination between the collaborators play a key role in the success of IS projects.

Our aim is to extend IS engineering methods in order to enhance their capability for anticipating the Strategy/Business/IS alignment requirements. The IS engineering method which will be just extended for illustrating our purpose is EKD-CMM, already applied in many professional contexts. However, the method chunks, which will be provided for the alignment requirements, should be generic because they have vocation to enhance any IS engineering method.

\section{REFERENCES}

Adams, R., Latimore, D., and Wong, D. (2003) Business and IT operational models in financial services: Beyond strategic alignment, IBM Institute for Business Value study.

Barrios, J. (2001) Une méthode pour la définition de l'impact organisationnel $d u$ changement. Thèse de Doctorat de l'Université de Paris 1, Janvier 2001.

Barrios, J., Nurcan, S. (2004) Model Driven Architectures for Enterprise Information Systems, CAISE'04, Springer Verlag, Riga, Latvia, 2004.

Bleistein, S. J., Cox, K., and Verner, J. (2005) Strategic Alignment in Requirements Analysis for Organizational IT : an Integrated Approach, 20th ACM Symposium on Applied Computing, track on Organisation Engineering, Santa Fe, USA.

Campbell, B., Kay, R. and Avison, D. (2004) Strategic Alignment: A Practitioner's Perspective, MCIS'04, Tunis Tunisia.

Henderson, J. C., Venkatraman, N., (1999), Strategic Alignement: Leveraging information technology for transformation organizations IBM Systems Journal, vol 38. No S2\&3. Adams Renner.

Jarke, M., Mylopoulos, J., Schmidt, J.M, and Vassilou, Y. (1990) DAIDA : Conceptual Modeling and Knowledge Based Support of Information Systems Development Process. Technique et Science Informatiques, 9 (2) : 122-133.

Kaplan, R., Norton, D. (1996) Balanced Scorecard Translating strategy into action, Harvard Business School Press (Ed.)

Longépé, C. (2004) Le projet d'urbanisation du SI -Démarche pratique avec cas concrets $-2{ }^{\text {ème }}$ édition, Dunod (Ed.)

Luftman, J. (2000) Assessing Business-IT alignment maturity. Communications of AIS, Volume 4, Article 14.

Luftman, J., Maclean, E. R. (2004) Key issues for IT executives. MIS Quarterly Executive, 3, 2004, p. 89-104.

Morton, M.S. (2001) L'Entreprise Compétitive au Futur. Les fiches de lecture de la Chaire D.S.O. CNAM - Organisation \& Système d'Information.

Nurcan, S., Edme, M. H. (2005) Intention Driven Modelling for Flexible Workflow Applications. SPIP Journal, Special issue on BPMDS.

Papazoglou, M.P., Van den Heuvel, W.J. (2000) Configurable Business Object for building evolving entreprise models and applications in vand er Aalst, Desel and Oberweis (eds) Business Process Management. Springer.

Rolland, C. (1998) A Comprehensive View of Process Engineering. In 10th CAISE'98, Pisa, Italy.

Sadiq, S., Orlowska, M. (1998) Dynamic Modification of Workflows. Technical Report No. 442. Department of Computer Science and Electrical Engineering, University of Queensland, Brisbane, Australia. October.

Scheer, A.W., Nüttgens, M. (2000) ARIS Architecture and Reference Models for Business Process Management. in van der Aalst, Desel and Oberweis (eds) Business Process Management, Springer.

Wegman, A. (2003) The Systemic Enterprise Architecture Methodology Business and IT Alignment for Competitiveness. LAMS-IC-EPFL CH-1015 Lausanne, Switzerland.

Wieringa, R.J., Blanken, H.M., Fokkinga, M.M., and Grefen, P.W.P.J. (2003) Aligning application architecture to the business context. CAiSE 03, p. 209-225. Springer. 